NBER WORKING PAPER SERIES

OFFSET AND STERILIZATION UNDER FIXED EXCHANGE
RATES WITH AN OPTIMIZING CENTRAL BANK

Nouriel Roubini

Working Paper No. 2777

NATIONAL BUREAU OF ECONOMIC RESEARCH

1050 Massachusetts Avenue

Cambridge, MA 02138

November 1988

I thank Alberto Giovannini and Jeff Sachs for an original suggestion for this paper and Kala Krishna and Sue Collins for helpful comments. Of course, all errors are mine. This research is part of NBER's research program in International Studies. Any opinions expressed are those of the author not those of the National Bureau of Economic Research. 
NBER Working Paper \#2777

November 1988

\section{OFFSET AND STERILIZATION UNDER FIXED EXCHANGE RATES WITH AN OPTIMIZING CENTRAL BANK}

\section{ABSTRACT}

The traditional approach to the estimation of the offset and sterilization equations can be criticized for the ad-hoc specification of the reaction function of the monetary authorities and the endogeneity of the domestic credit and foreign reserve variables in the estimated equations. The paper proposes an alternative analytical model where the sterilization and offset equations are derived from an explicit maximization problem solved by the monetary authority. In such a model, the optimal intervention and sterilization policies of the monetary authority are shown to be dependent on the different disturbances hitting the economy and the preferences of the monetary authority. In particular, under a wide range of domestic and foreign disturbances the optimal response of the central bank will lead to negatively correlated comovements of domestic credit and foreign reserves if the central bank cares more about the interest rate smoothing objective relative to the foreign exchange reserve stabilization goal. Conversely, positive correlations between domestic credit and foreign reserves will be observed if the foreign reserve objective is dominant.

Nouriel Roubini

Department of Economics Yale University P. O. Box 1972 Yale Station New Haven, CT 06520 


\section{Introduction}

In a small open economy under a regime of fixed exchange rates and high capital mobility, an attempt to expand the money supply through a domestic credit expansion will lead to offsetting reductions in foreign exchange rate reserves: in the limiting case of perfect capital mobility and asset substitutability the money supply is endogenous and the offset coefficient will be equal to minus one, i.e. any domestic credit expansion will lead to a one-to-one fall in foreign reserves. In this case any attempt to sterilize the effects of foreign exchange interventions on the money supply would be self-defeating and engineer further foreign reserve losses.

More recent studies of fixed rate regimes and the European Monetary System in particular ${ }^{1}$ have stressed that, while the previous argument is correct for a small open economy bearing the burden of pegging the exchange rate (a "follower" or "periphery" country). offset coefficients might be very small and sterilization policies feasible for a "leader" or "center" country in a fixed exchange rate regime, i.e. the country that is allowed by the "rules of the game" to set independently its monetary policy.

More strongly, it has been suggested ${ }^{2}$ that a way to test empirically whether a fixed rate regime like the EMS works asymmetrically (with a leader country setting the monetary policy of the union and the followers adjusting their money supplies in order to peg the exchange rate) or symmetrically (with the burden of pegging the

1. See Roubini (1988 a,b,c) and Giavazzi and Giovannini (1988 a,b).

2. See Roubini (1988 a, c). 
exchange rate cooperatively shared by all the members of the union) is to estimate the offset and sterilization coefficients for the members of the union. In particular, one would expect that:

(a) If a fixed rate regime is characterized by leadership, the offset coefficient of the leader will be close to zero while the offset coefficient of the followers will be close to negative one (in the absence of capitai controls). Conversely, in a symmetric regime offset coefficients will be negative but smaller than one for all the member countries.

(b) In a regime of leadership, estimates of the sterilization parameter should be close to zero for follower countries given their inability to sterilize foreign reserve flows and close to minus one for the leader country.

A large literature in open economy macroeconomics in the past decade has analyzed the interactions between domestic credit policies, foreign exchange rate reserves and money supplies under a regime of fixed exchange rates ${ }^{3}$. On one side, estimates of capital flow equations for the Bretton Woods period of fixed rates were performed in order to obtain estimates of the offset coefficient, i.e. how much of a domestic credit expansion is offset by a reduction in foreign exchange reserves. On the other side, sterilization equations for Bretton Woods period and the successive period of managed rates were estimated to verify whether central banks are able to sterilize the effects of foreign exchange rate interventions on their money supplies. More

3. See Argy and Kouri (1974), Kouri and Porter (1974), Herring and Marston (1977 a, b), Kouri (1975), Marston (1980), Neumann (1978. 1984), Obstfeld (1978, 1982a, 1982b) among the others. 
recently, a number of authors have tried to test the hypothesis of a "German leadership" of the EMS versus a "cooperative" model of the EMS by estimating sterilization and offset equations for the most recent EMS period ${ }^{4}$.

The objective of this paper is twofold:

(1) To show that the traditional, and generally used, approach to the estimation of the offset and sterilization equations is flawed because of the ad-hoc specification of the reaction function of the monetary authorities and the endogenelty of the domestic credit and forelgn reserve variables in the estimated equations.

(2) To propose an alternative analytical model where the sterllization and offset equations are derived from an explicit maximization problem solved by the monetary authority. In such a model, an optimal reaction function for the monetary authority is derived and the optimal intervention and sterilization policies are shown to be dependent on the different disturbances hitting the economy and the preferences of the monetary authorities.

The plan of the paper is the following. Section 2 discusses the problems with the traditional approach to the specification and estimation of the offset and sterilization equations. Section 3 presents the alternative model of a central bank behavior and shows the implications of this model for the analysis of the sterilization

4. Roubini (1988 a) estimates sterlization and offset equations for the EMS countries. Mastropasqua, Micossi and Rinald1 (1988) and Giavazzi ( 1987 ) estimate sterilization equations. Glavazzi and Giovannini ( 1988 b) abandon the structural reaction function estimation approach and attempt to estimate the reduced form reaction functions of the monetary authorities of the EMS. 
policies of the monetary authority. Section 4 concludes and suggest some avenues for further research.

2. The Traditional Approach to the Sterilization and offset Equations.

The basic approach followed by all the studies of sterilization policies has been to specify an arbitrary reaction function of the monetary authorities relating the change in domestic credit $\left(D_{t}\right)_{t}$ to the change in net foreign assets (DNFA ${ }_{t}$ ) and a set of other policy objectives (usually the inflation rate (INF $t_{t}$ ) and deviation of output from trend $\left(\right.$ YGAP $\left._{t}\right)$ :

$\mathrm{DDC}_{t}-\alpha_{0}+\alpha_{1} \mathrm{DNFA}_{t}+\alpha_{2} \mathrm{INF}_{t}+\alpha_{3} \mathrm{YGAP}_{t}+u_{t}$

In equation (a), the parameter $\alpha_{1}$ is an estimate of the degree of sterilization of foreign reserves followed by the monetary authorities. For given levels of the inflation rates and deviation of output from trend, $\alpha_{1}$ measures how much of a change in foreign exchange reserves deriving from interventions in the exchange rate market is sterilized by the monetary authorities. For $\alpha_{1}=-1$ the sterilization is complete while $\alpha_{1}>-1$ implies a degree of sterilization that is less than full. The inflation rate enters in the reaction function with a negative sign $\left(\alpha_{2}<0\right)$ since the monetary authority will react to an increase in the inflation rate with a contraction of domestic credit while the output gap variable will have a negative sign $\left(\alpha_{3}<0\right)$ because the central 
bank will react to a fall of output relative to its trend by expanding domestic credit ${ }^{5}$.

One of the problems with equation (a) is the endogeneity of the net foreign asset variable in the reaction function (a): because of this endogeneity OLS estimates of the sterilization coefficient will be inconsistent. This endogeneity of the reserve variable derives from the fact that, under a system of fixed exchange rate, a domestic credit expansion will be offset by a fall in foreign exchange rate reserves; the offset coefficient will be greater the larger is the degree of capital mobility and asset substitutability between domestic and foreign assets. It then follows that, in a reaction function like (a), the net foreign asset is an endogenous variable and that high coefficients on the foreign asset varlable in the estimated reaction function might be wrongly interpreted as high sterilization

5. Herring and Marston (1977a) estimated a reaction function of the Bundesbank for the 1960-1971 and found that during each quarter of that perlod approximately 90 of the change in foreign reserves was sterilized: this suggest a policy of almost complete sterilization of foreign reserve flows. Obstfeld (1982) estimated a similar reaction function for the 1975-81 period and found that the sterilization coefficient was not significantly different from minus one, a result that would imply a policy of complete sterilization. Neumann (1984), using Bundesbank data that distinguished between active and passive intervention and estimating a reaction function for the 1974-1981 period found that the sterilization coefficient was negative and large but less than unity. Vaubel (1980) advanced a more extreme "punishment" hypothesis by claiming that the Bundesbank tried to impose its monetary policy dominance over the other European central banks by "punishing" them whenever it was forced to intervene in support of the European currencies participating to the pre-EMS "snake"; according to this hypothesis the punishment consisted in overcompensating the effects on the German monetary base of its foreign exchange interventions (a sterilization coefficient greater than one in absolute value). The results of Obstfeld (1983) and Neumann (1984) do not confirm this "punishment" hypothesis; however, they provide ample evidence that sterilization of reserve flows was systematically pursued by the Bundesbank throughout the 1970s. 
coefficients; in reality, they might just represent high offset coefficient. In other terms, while equation (a) interprets the relation between domestic credit and net foreign assets as a causal relation that goes from forelgn assets to domestic credit, the actual relation could go from domestic credit to foreign assets.

A similar and dual endogeneity problem arises in the estimation of capital flow equations where the objective is to obtain estimates of the offset coefficient. The standard approach to the estimation of the offset parameter ${ }^{6}$ starts from the asset markets equilibrium conditions and the central bank balance sheet and derives a reduced form equation that relates the capital account of the balance of payments (CAP) to the change in domestic credit (DDC), the current account balance (CURR), the change in foreign interest rates $\left(D R^{*}\right)$, the change in nominal income (DY) and a vector of other exogenous variables (EXOG) ${ }^{7}$ :

$\mathrm{CAP}_{t}-\beta_{0}+\beta_{1} \mathrm{DDC}_{t}+\beta_{2} \mathrm{CURR}_{t}+\beta_{3} \mathrm{DR}_{t}^{*}+\beta_{4} \mathrm{DY}_{t}+\mathrm{EXOG}_{t}^{\prime} \beta+\epsilon \epsilon_{t}$

In equation (b), the parameter $\beta_{1}$ is an estimate of the offset coefficient. The main problem with ols estimates of equation (b) is that domestic credit is an endogenous variable when the central bank

6. This approach is followed by Argy and Kouri (1974). Kouri and Porter (1974), Kouri (1975), Neumann (1978), Herring and Marston (1977a,b), Obstfeld (1978, 1982a, 1982b).

7. An analytical derivation of equation (b) in described in section 3 . 
follows a sterilization policy; OLS estimates of the parameters of equation (2) will then be inconsistent 8 .

Given the inconsistency of the OLS estimates of the offset and sterilization parameter because of the endogenelty of the net foreign asset and domestic credit variables in these equations, what will be the direction of the bias of the ols estimators of the sterilization and offset coefficients? It can be shown that ols estimators will bias both coefficients towards minus one. Consider again equation (a) and (b) and the definition of the change in net foreign assets as the sum of the current account and capital account (equation (c)):

$\mathrm{DDC}_{t}=\alpha_{0}+\alpha_{1} \mathrm{DNFA}_{t}+\alpha_{1} \mathrm{INF}_{t}+\alpha_{2} \mathrm{YGAP}_{t}+u_{t}$

$\mathrm{CAP}_{t}-\beta_{0}+\beta_{1} \mathrm{DDC}_{t}+\beta_{2} \mathrm{CURR}_{t}+\beta_{3} \mathrm{DR}_{t}^{*}+\beta_{4} \mathrm{DY}_{t}+\mathrm{EXOG}_{t}^{\prime} \beta+\epsilon_{t}$

$\operatorname{DNFA}_{t}=\mathrm{CURR}_{t}+\mathrm{CAP}_{t}$

Substituting (c) in (a), (a) and (b) can be rewritten in compact form as:

$D D C_{t}=\alpha_{1} \mathrm{CAP}_{t}+\alpha^{\prime} \mathrm{x}_{1 t}+u_{t}$

$\mathrm{CAP}_{t}-\beta_{1} \mathrm{DDC} C_{t}+\beta^{\prime} \mathrm{X}_{2 t}+\epsilon_{t} \quad\left(\mathrm{~b}^{\prime}\right)$

8. While most of the work on the offset coefficient is based on OLS estimates, some authors (Argy and Kouri (1974) and Obstfeld (1982a, b)) use instrumental variables and estimate equation (2) by two-stage least squares. 
where $x_{1}$ and $x_{2}$ are the vectors of the exogenous regressors in equations (a) and (b).

Given the endogeneity of DNFA in equation (a) and of DDC in equation (b), these explanatory variables are correlated with the error terms in their respective equations and OLS estimates of both $\alpha_{1}$ and $\beta_{1}$ are inconsistent. It can be easily shown that the bias on $\alpha_{1}$ and $\beta_{1}$, the estimated values of $\alpha_{1}$ and $\beta_{1}$, is given by the expressions (d) and (e):

$\operatorname{Plim}\left(\hat{a}_{1}-a_{1}\right)=\frac{\beta_{1}\left(1-\alpha_{1} \beta_{1}\right) \sigma_{\mathrm{u}}^{2}}{\beta^{\prime} \mathrm{V}\left(\mathrm{X}_{2}\right) \beta+\beta_{1}^{2} \sigma_{\mathrm{u}}^{2}+\sigma_{\epsilon}^{2}}$

$\operatorname{Plim}\left(\hat{\beta}_{1}-\beta_{1}\right)=\frac{\alpha_{1}\left(1-\beta_{1} \alpha_{1}\right) \sigma_{\epsilon}^{2}}{\alpha^{\prime} \mathrm{V}\left(\mathrm{X}_{1}\right) \alpha+\alpha_{1}^{2} \sigma_{\epsilon}^{2}+\sigma_{\mathrm{u}}^{2}}$

where $V\left(X_{1}\right)$ and $V\left(X_{2}\right)$ are the asymptotic variance-covariance matrices $\mathrm{x}_{1}$ and $\mathrm{x}_{2}$. Stability of the model requires that $\alpha_{1} \beta_{1}<1$ that will always be satisfled as long as the sterilization coefficient $\left(\beta_{1}\right)$ and offset coefficlent $\left(\alpha_{1}\right)$ are not smaller than minus one ${ }^{9}$. Given that $\alpha_{1}$ and $\beta_{1}$ are negative, the formulas (d) and (e) Imply that the OLS bias

9. Assuming realistically that the offset effect is, at the maximum, equal to minus one $\left(-1<\alpha_{1}<0\right)$ and that sterilization is, at the maximum, complete $\left(-1<\beta_{1}<0\right)$, this stability condition is always satisfied. The offset coefficlent is bounded downward by minus one only if the exchange rate is pegged with certainty. However, if exchange rate realignments are possible, a "peso problem" will result and the estimated offset coefficlent might be greater than unity in absolute value. In fact, close to realignments, expected changes in the exchange rate may lead to offset of domestic credit on reserves that are more than one-to-one. 
In the estimation of $\alpha_{1}$ and $\beta_{1}$ is negative, 1.e. OLS estimates of both parameters will be biased towards minus one. This means that oLS estimates of the sterilization coefficient will tend to show high degrees of sterilization in all the countries when the true value of these sterilization policies is smaller; similarly, the estimates of the offset coefficient will be blased towards high measures of offset.

In order to deal with the simultanelty bias deriving from the endogeneity of the reserve and domestic credit variables, the approach followed by many authors ${ }^{10}$ has been to use instrumental variables to estimate (a) and (b) by two-stage least squares (2SLS). This route to the solution of the simultaneity bias problem is however ridden with a number of problems.

First of all, consistent 2SLS estimates of the sterilization coefficlent suggest that most of the countries in a fixed rate regime like the Bretton Woods system or the EMS are able to sterilize their reserves flows (the estimates of the sterilization coefficient are highly negative). This is however incompatible with the operation of a fixed rate regime where only one member, the leader country, can systematically sterilize reserve flows ${ }^{11}$. Moreover, the estimates of the parameters on the macro targets in the reaction function (a) (inflation and output gap) are generally insignificant and often of the wrong sign suggesting that the reaction function might be mispecified.

10. Argy and Kour1 (1974), Herring and Marston (1977), Obstfeld (1982a, b), Mastropasqua, Micossi and Rinaldi (1988), Roubini (1988 a).

11. For the instability of reserve flows when more than one country tries to sterllize see De Grauwe (1977), Aok1 (1977), Glavazzi and Giovannini (1988a, b) and Roubini (1988a, c). 
Secondly, and more importantly, the reaction function (a) is not derived from any particular maximization problem solved by a monetary authority but rather presented in a ad-hoc manner. In particular, any maximization problem where output and inflation enter in the loss function of the central bank could not lead to a reduced form reaction function like (a) where the two targets appear. The first order conditions of such a problem would imply that these final targets would disappear from the reduced form and be supplanted by the underlying shocks and/or exogenous variables to which the central bank is reacting. In view of this substantial misspecification of the reaction function, it is not surprising that "consistent" estimates of the parameters of this reaction function give insignificant estimates of the two macro targets and are unable to identify the true value of the sterilization coefficient.

Third, given the misspecification of the sterilization function, consistent instrumental variable estimator of the offset coefficient in the capital flow equation (b) are also unable to identify the true value of the offset parameter.

Given the nature of the problems with the traditional approach to the estimation of the offset and sterilization function, the next section presents a model where these functions are derived from the an explicit maximization problem solved by the monetary authority. In that approach, it can be shown that speaking of a unique value of the sterilization parameter becomes meaningless because the optimal sterilization and foreign exchange intervention policies are no 
constant but dependent on the disturbances hitting the economy and the preferences of the monetary authority.

\section{Offset and Sterilization with an Optimizing Central Bank}

We have seen in the previous section that the main problems with the traditional approach to the estimation of sterilization and offset functions are twofold: first, the standard reaction function used in the literature on sterilization is assumed in ad hoc manner and is not derived from any specific maximization problem of the central bank; second, the reduced form of a correctly specified offset function will also depend on the optimization problem solved by the central bank. Methodologically, a more correct approach is to consider explicitly the problem faced by a monetary authority and derive an optimal reaction function where the central bank chooses simultaneously its optimal intervention and sterilization policies by reacting to the various disturbances that hit the economy.

In this section we will try to address this issue by considering a simple financial model of a small open economy with fixed exchange rates and derive the reaction function for its monetary authority. In order to consider the implications of imperfect capital mobility and asset substitutability we will present a model where the degree of asset substitutability between domestic and foreign asset is not complete $^{12}$

12. A interesting recent paper by Giavazzi (1987) considers the policy trade-offs of a central bank trying to stabilize the money supply

following current account and asset preference shocks. However, this 
Consider the following model of the financial bloc of a small open economy under fixed rates:

$H-R+D$

$W=B^{d}+H+F^{d}$

$B=B^{d}+D$

$H-h_{0} r+h_{1} r^{\star}+h_{2} Y+h_{3} W$

(4) $h_{0}<0, h_{1}-0, h_{2}>0, h_{3}>0$

$B^{d}-b_{0} r-b_{1} r^{\star}+b_{2} Y+b_{3} W$

(5) $\mathrm{b}_{0}>0, \mathrm{~b}_{1}>0, \mathrm{~b}_{2}<0, \mathrm{~b}_{3}>0$

$F^{d}-f_{0} r+f_{1} r^{\star}+f_{2} Y+f_{3} W$

(6) $\quad \mathrm{f}_{0}<0, \mathrm{f}_{1}>0, \mathrm{f}_{2}<0, \mathrm{f}_{3}>0$

where:

$$
\begin{aligned}
& \left(h_{0}+b_{0}+f_{0}\right)=0 \\
& \left(h_{1}-b_{1}+f_{1}\right)=0 \\
& \left(h_{2}+b_{2}+f_{2}\right)=0 \quad\left(h_{2}+b_{2}\right)>0 \\
& \left(h_{3}+b_{3}+f_{3}\right)=1
\end{aligned}
$$

and: $\quad \mathrm{H}=\mathrm{High}$ powered money

contribution does not present an explicit optimization model for the behavior of the central bank. 


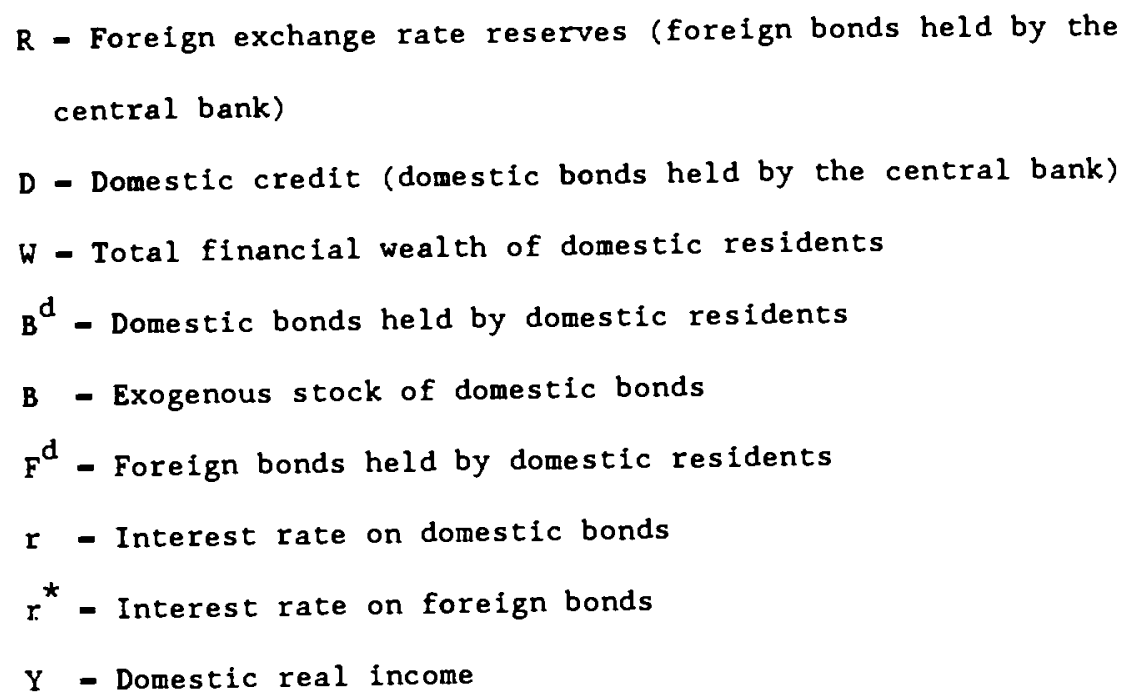

We will concentrate on the financial side of the model and consider a short term analysis; then we can take income ( $Y$ ) as given; $W$, domestic wealth is also assuned to be exogenous and its change is equal to the current account of the balance of payments. The country is small and therefore the foreign interest rate will also be exogenous. However, the specification of the asset demand functions does not impose an assumption of perfect asset substitutability so that the interest parity condition between domestic and foreign asset does not necessarily hold 13 .

Given the financial flavor of the model we do not assume that the objective of the central bank is to stabilize output and inflation as the standard sterilization literature does. We will rather assume that, in the short run that we are considering, the objective of the central

13. As a special case of the model, we can get perfect asset substitutability for $b_{0}-b_{1}=\infty$. We will discuss this special case below. 
bank is to stabilize foreign exchange reserves and domestic interest rates. The inclusion of foreign exchange reserves can be explained by the argument that central banks under fixed exchange rates care about their level of net foreign reserves $14 \quad 15$. The interest rate target depends on the short term nature of the model: for given expected values of the real variables of the system and the inflation rate, the central bank might want to reduce the short term volatility of interest rates ${ }^{16}$. We can then write the loss function of the central bank as:

$L=\frac{1}{2}(r)^{2}+\alpha \frac{1}{2}(R)^{2}$

where $\alpha$ is the weight given to the foreign reserves objective relative to the interest rate smoothing goal in the loss function. The central

14. Theoretically, if the central bank could borrow foreign reserves in unlimited amounts, it might not care about its level of reserves. However, there is ample evidence that central banks care about their level of reserves. Roubini (1987 a) discussed at length why that is the case. Among the various reasons: first, if central banks care about their net foreign reserves borrowing gross reserves would not affect their amount net of borrowing. Second, the opportunity cost of borrowing reserves is likely to be positive and its marginal cost increasing. Third, liquidity constraints in the international capital markets and/or "conditionality" in borrowing (from IMF and/or the EMS borrowing facility) limit the ability to borrow and/or increase its marginal cost.

15. The assumption of a foreign reserve objective is the standard one in model of strategic policy interactions under fixed exchange rate regimes; in this regard, see the seminal contributions of Hamada collected in Hamada (1985).

16. In a recent paper Barro (1988) makes the same assumption of an "interest rate smoothing" objective of the central bank. 
bank uses domestic credit (D) as its policy instrument to control its two objectives 17 .

Using equations (1)-(6) we can write the reduced form solution for the interest rate $(r)$ and foreign reserve (R) variables as:

$r-\frac{b_{1}}{b_{0}} r^{*}+\frac{1}{b_{0}}\left(B-D-b_{2} Y-b_{3} W\right)$

$R=\frac{b_{1}}{b_{0}} h_{0} r^{*}+\left(h_{0} / b_{0}\right) B+\left(h_{2}-\left(h_{0} / b_{0}\right) b_{2}\right] Y+\left[h_{3}-\left(h_{0} / b_{0}\right) b_{3}\right] W$

$$
-\left(1+\frac{h_{0}}{b_{0}}\right) \quad D
$$

As can be seen from equation (9) the offset of a domestic credit expansion on foreign reserves is negative but less than unity 18 ; in the special case of perfect asset substitutability where $\left(b_{0}-b_{1}-\infty\right)$ we get:

17. One could equivalently assume that forelgn reserves are the policy instrument in which case domestic credit (D) becomes endogenous. The results of the model are identical under the two alternative as sumptions.

18. Equation (9) is essentially identical to the semi-reduced form capital flow equation (b) estimated in the studies of the offset coefficient. The endogeneity of the domestic credit variable (D) in this equation is the source of the problem with the traditional estimates of this function. 
$r=r^{\star}$

$\frac{d R}{d D}=-1$

i.e. domestic rates are always equal to foreign ones and the offset coefficient is equal to minus one.

Given the solution for the interest rate and the foreign reserves in equations (8) and (9), the problem of the central bank is to minimize the loss function (7) with respect to the policy instrument (D) subject to the system (8)-(9). Taking the first order conditions and grinding through the algebra, one obtains the following reaction function for the domestic credit variable:

$D-\left[\frac{b_{0}^{2}}{1+a\left(h_{0}+b_{0}\right)^{2}}\right] *\left(\frac{b_{1}}{b_{0}}\left[1 / b_{0}+\alpha^{2} h_{0}\left(1+h_{0} / b_{0}\right)\right] r^{*}+\right.$

$\left[\frac{1}{b_{0}^{2}}+\alpha^{2}\left(1+h_{0} / b_{0}\right) h_{0} / b_{0}\right] B+\left[\frac{b_{2}}{b_{0}^{2}}+\alpha^{2}\left(1+h_{0} / b_{0}\right)\left(h_{2}-\frac{h_{0}}{b_{0}} b_{2}\right)\right] Y+$

$$
\left[\frac{b_{3}}{b_{0}^{2}}+a^{2}\left(1+h_{0} / b_{0}\right)\left(h_{3}-\frac{h_{0}}{b_{0}} b_{3}\right)\right] w,
$$


Substituting the reaction function (11) in the equations (8)-(9) for $r$ and $R$, we obtain the final reduced form for the interest rate and the foreign reserves:

$r=\left[\frac{b_{1} \alpha^{2}\left(h_{0}+b_{0}\right)}{1+\alpha^{2}\left(b_{0}+h_{0}\right)^{2}}\right] r^{*}+\left[\frac{\left.-a^{2}\left(b_{0}+h_{0}\right)\right)\left(h_{3}+b_{3}\right)}{1+a^{2}\left(b_{0}+h_{0}\right)^{2}}\right] w+$ $\left[\frac{\left.-a^{2}\left(b_{0}+h_{0}\right)\right)\left(h_{2}+b_{2}\right)}{1+\alpha^{2}\left(b_{0}+h_{0}\right)^{2}}\right] Y+\left[\frac{\alpha^{2}\left(h_{0}+b_{0}\right)}{1+\alpha^{2}\left(b_{0}+h_{0}\right)^{2}}\right] B$

$R=\left[\frac{-b_{1}}{1+a^{2}\left(h_{0}+b_{0}\right)^{2}}\right] r^{*}+\left[\frac{\left(h_{3}+b_{3}\right)}{1+a^{2}\left(h_{0}+b_{0}\right)^{2}}\right] w+$

$\left[\frac{-1}{1+a^{2}\left(h_{0}+b_{0}\right)^{2}}\right] B+\left[\frac{\left(h_{2}+b_{2}\right)}{1+a^{2}\left(h_{0}+b_{0}\right)^{2}}\right] Y$

One can observe that in the reduced form equations for the domestic credit reaction function (11) and the offset function for reserves (13), these two variables depend only on the exogenous variables and disturbances hitting the system. In particular, the two endogenous variables do not depend on each other in these reduced 
forms; in these sense these solution differ from the standard semireduced sterilization and capital-flow functions found in the literature where domestic credit and foreign reserves depended on each other.

We will now consider the movements of interest rates, domestic credit and foreign reserves following a number of exogenous disturbances to discuss the circumstances under which it is likely to observe the large and negative empirical correlations between domestic credit and foreign reserves found in the estimation of offset and sterilization equations 19.

\section{A. A foreign interest rate shock}

Let us start by considering a foreign disturbance in the form of an increase in the foreign interest rate $\left(r^{*}\right)$. From equation (11), the effect of the change in $r^{*}$ on domestic credit, foreign reserves and the interest rate is:

$\frac{d D}{d r^{*}}-\frac{b_{1}}{b_{0}}\left[\frac{b_{0}^{2}}{1+\alpha\left(h_{0}+b_{0}\right)^{2}}\right]\left[1 / b_{0}+\alpha^{2} h_{0}\left(1+h_{0} / b_{0}\right)\right]<0$

$\frac{d R}{d r_{\star}}=\frac{-b_{1}}{1+a^{2}\left(h_{0}+b_{0}\right)^{2}}<0$

19. See Roubini (1988 a). 
$\frac{d r}{d r^{*}}=\left[\frac{b_{1} \alpha^{2}\left(h_{0}+b_{0}\right)}{1+\alpha^{2}\left(b_{0}+h_{0}\right)^{2}}\right] \leq 1$

The optimal response of the monetary authority depends on the degree of substitutability between domestic and foreign assets; consider first the case of perfect asset substitutability where $b_{0}-b_{1}-\infty$; in this case, equations (11)-(13) imply:

$\frac{d D}{d r^{\star}}-h_{0}<0 \quad \frac{d R}{d r^{*}}=0 \quad \frac{d r}{d r^{*}}=1$

If assets are perfectly substitutable, the domestic interest rate must equal the foreign one; then, any attempt to stabilize the domestic interest rate in face of the foreign shock would be futile. The optimal response of the central bank in then to forget the interest rate target and rather attempt to stabilize the level of foreign reserves. The foreign rate shock, in the absence of a reaction by the central bank, would lead to a loss of reserves (see equation (13)); however, by reducing domestic credit by the amount by which money demand has fallen following the shock in $r^{*}$ ( 1 .e. by $h_{0}$ ) the central bank in able to stabilize completely the level of foreign reserves. In this case, then, we would observe empirically a fall in domestic credit with no change in foreign reserves, 1.e.:

$\frac{d R}{d D}=0$ 
We can consider next the more general case where assets are less than perfectly substitutable; in this case the optimal response of domestic credit depends on the relative weight of the interest rate and foreign reserve targets in the loss function (7). The trade-off faced by the monetary authority is clear: given the rise in the foreign rate, it can stabilize interest rates by expanding domestic credit (see equation (8)) in which case it would lose foreign reserves (see equation (9)) or it can stabilize foreign reserves by contracting domestic credit in which case it has to allow the domestic interest to rise towards the higher foreign one. If the central bank cares about both objectives $(0<\alpha<\infty)$, then it will contract domestic credit if it cares more about reserves while it will expand credit if the smoothing of interest rates is more important. More formally, domestic credit will be expanded or contracted on the basis of the following critical condition:

$$
\frac{d D}{d r^{\star}}<0 \quad \text { if } \alpha<\frac{1}{\left(-b_{0}\left(b_{0}+h_{0}\right)\right)^{(1 / 2)}}
$$

What will occur to the level of foreign reserves? Equation (15) shows that, independently of what happens to domestic credit, foreign reserves will unequivocally fall (as long as $b_{0}<\infty$ ). The result is again intuitive: in the absence of a reaction of domestic credit, the rise in $r^{*}$ would lead to a fall in reserves; then, if domestic credit 
in (14) in increased in order to stabilize the interest rate (low $\alpha$ case from (18)), the foreign reserves will fall even more. However, even if domestic credit is contracted (the case of a high value of $\alpha$ in (18)), the optimal reaction of $D$ is not enough to prevent some fall in foreign reserves; then, in either case, foreign reserves must fall following the rise in $r^{*}$.

The empirical implication of this result is that we will observe a negative correlation of domestic credit and foreign reserves if the central bank does not care a lot about reserves and tries to stabilize interest rates in the short run (a low value of $\alpha$ ); while we will observe comovements in the same direction of $R$ and $D$ if the main objective of the monetary authority is to stabilize the level of foreign reserves (a high value of $\alpha$ ).

This role of the preferences of the monetary authority can be further discussed and formally derived by considering how the optimal reaction to a foreign shock depends on $\alpha$, the relative weight of the two objectives in the reaction function. Consider the reaction to a foreign interest rate shock in the two limiting cases where $a=0$ (the central bank cares only about interest rate smoothing) and $\alpha-\infty$ (the central bank cares only about foreign reserves):

$\underline{a-0}:$

$\frac{d D}{d r^{\star}}--\frac{d R}{d r^{\star}}-b_{1}>0$ or $\frac{d D}{d R}=-1$ 
$\underline{\alpha-\infty}:$

$\frac{d D}{d r^{*}}-\frac{h_{0} b_{0}}{\left(b_{0}+h_{0}\right)}<0 \quad \frac{d R}{d r^{*}}-0$

If the monetary authority does not care about reserves $(\alpha-0)$, we will observe comovemnts of reserves and domestic credit that are negative and perfectly correlated. As $\alpha$ increases, this correlation becomes smaller (in absolute value) and turns positive for $\alpha$ rising above the critical value in condition (18).

One implication of these results for the EMS is that the large and negative correlations of domestic credit and foreign reserves found in sterilization studies of the EMS ${ }^{20}$ even for the case of the smaller "follower" countries could be consistent with a view of these EMS central banks as being more concerned about the short term stabilization of interest rates relative to the objective of maintaining their level of foreign reserves. In this sense, even for a follower country it would be optimal to sterilize partially the foreign reserve losses following an increase in the level of foreign interest rates. This sterilization is feasible as long as domestic and foreign assets are less than perfectly substitutable $\left(b_{0}-b_{1}<\infty\right)$ so that the offset coefficient is less than unity; but its foreign reserve loss cost becomes greater as the degree of substitutability becomes larger. To conclude the discussion of the effects of a foreign interest

20. See Roubini (1988 a). 
rate shock we can consider the case of zero asset substitutability (or no capital mobility). In this case $b^{1}$ is equal to zero and we then get:

$\frac{d D}{d r^{\star}}=\frac{d R}{d r^{\star}}-\frac{d r}{d r^{*}}=0$

If assets are not substitutable, foreign interest rate shocks do not affect the domestic variables in which case the optimal policy is to do nothing; in this case neither domestic credit nor foreign reserves will be affected by the shock.

B. A current account shock

We will consider next the effect of an exogenous current account (CA) shock represented here by a change in financial wealth:

$\mathrm{CA}=\mathrm{d} \mathrm{W}$

In this case the solution for the domestic credit and the foreign reserves will be:

$\frac{d D}{d W}=\frac{-b_{3}+a^{2}\left(b_{0}+h_{0}\right)\left(h_{3} b_{0}-h_{0} b_{3}\right)}{1+\alpha^{2}\left(h_{0}+b_{0}\right)^{2}}<0$




$$
\begin{aligned}
\frac{d R}{d W} & =\frac{-b_{3}+\alpha^{2}\left(b_{0}+h_{0}\right)\left(h_{3} b_{0}-h_{0} b_{3}\right)}{1+a^{2}\left(h_{0}+b_{0}\right)^{2}}\left(1+\frac{h_{0}}{b_{0}}\right)+\left(h_{3}-b_{3} \frac{h_{0}}{b_{0}}\right) \\
& =\frac{\left(h_{3}+b_{3}\right)}{1+\alpha^{2}\left(h_{0}+b_{0}\right)^{2}}>0
\end{aligned}
$$

In the absence of a reaction by the monetary authority, equations (8) and (9) show that the current account shock would lead to an increase in foreign reserves and a fall in the domestic interest rate. Then, the central bank can try to stabilize the domestic interest rate by reducing domestic credit (see equation ( 8 )) but this would further increase the level of foreign reserves above its targeted level; conversely, the central bank might want to stabilize the level of reserves (by expanding domestic credit as in equation (9)) but this policy choice would lead to a further decline of interest rates. The optimal choice of the central bank will again depend on the relative weight of the two objectives; if it cares more about interest rates (a low $\alpha$ ) it will contract credit; otherwise ( a high $\alpha$ ) it will expand credit to stabilize reserves; more formally, it is simple to show that:

$$
\frac{d D}{d W}<0 \text { for } \quad \alpha^{>}\left\{\frac{b_{3}}{\left(b_{0}+h_{0}\right)\left(h_{3} b_{0}-h_{0} b_{3}\right)}\right\}^{(1 / 2)}
$$


Unlike the effect on domestic credit, the effects of the current account shock on foreign reserves is unambiguous as can be seen from equation (23). In the absence of a domestic credit reaction by the central bank, the foreign reserves would increase following the current account shock; then, if the central bank contract domestic credit to stabilize interest rates (the case of a low value od $\alpha$ ) the foreign reserve will increase even further; however, even if domestic credit is contracted (case of a high $\alpha$ ), the foreign reserves would still rise because the direct positive effects of the current account shock on reserves dominates the secondary effect coming from the domestic credit reaction of the monetary authority.

It then follows that if the monetary authority cares more about smoothing interest rates (low $\alpha$ ) we will observe empirically large and negative correlations of domestic credit and foreign reserves following current account shocks; while we will observe positive comovements of the two variables if the central bank leans towards stabilizing foreign reserves 21 .

We will turn now to some special cases by considering the current account shock under the assumption of perfect asset substitutability $\left(b_{0}-b_{1}-\infty\right)$; in this case we obtain:

$\frac{d D}{d W}=h_{3}>0 \quad \frac{d R}{d W}=0 \quad \frac{d r}{d W}=0$

21. Note the symmetry of this result with the one obtained in the case of a foreign interest rate shock. 
Given the perfect substitutability of domestic and foreign assets, the domestic interest rate does not change. In the absence of a policy reaction, foreign reserves would increase following the current account shock; then, the central bank can completely insulate the effect of the shock on the level of foreign reserves by expanding the domestic credit; then, the increased money demand following the wealth shock is satisfied through the increase in domestic without any effect on foreign reserves 22 . In this case we would then observe an increase in domestic credit with no change in foreign reserves.

We can finally consider the effects of the preferences of the central bank on the outcome of a current account shock. As discussed above the more (less) the central bank cares about interest rate smoothing (foreign reserve stabilization) the greater the contraction in domestic credit will be following a current account shock and the greater the expansion of foreign reserves. In the limit when $\alpha=0$, we obtain:

$\underline{\alpha-0}:$

$\frac{d D}{d W}--b_{3}<0 \quad \frac{d R}{d W}-\left(h_{3}+b_{3}\right)>0$

22. Alternatively, in the framework of Giavazzi (1987) where the central cares only about domestic interest rates, the case of perfect capital mobility will automatically insure that domestic interest rate is stabilized and that "the central bank is relieved from the burden of monitoring the domestic money market". 
and:

$\frac{d D}{d R}--\frac{b_{3}}{b 3+h_{3}} \geq-1$

In this case the observed empirical correlation between domestic credit and foreign reserves will be negative and tending to minus one if the money demand elasticity relative to wealth is small $\left(h_{3}-0\right)$. Again, as in the case of foreign interest rate shocks, the observation of large negative correlation of domestic credit and foreign reserves observed in the EMS countries could be interpreted as the optimal response of a central bank caring about interest rate stabilization in the presence of exogenous current account shocks. Similarly, the model implies that negative current account shock will lead to losses in foreign reserves and increases in domestic credit as the central bank tries to prevent the increase in domestic interest rates caused by the current account disturbance; in this case, the sterilization of these foreign reserve losses is feasible as long as domestic and foreign asset are not perfectly substitutable. It must also be observed that this interest rate smoothing objective becomes increasingly costly, in terms of foreign reserves losses, as the degree of substitution between domestic and foreign assets increases and the offset coefficient becomes greater.

C. An increase in domestic bonds 
We consider next the case of a domestic bond disturbance, i.e. an increase in the supply of domestic bonds deriving, for example, from the bond financing of a fiscal shock.

Equation (8)-(9) show that the impact effect of the shock, in the absence of a central bank optimal reaction, leads to an increase of interest rates and a fall in foreign exchange reserves. Interest rate have to rise to absorb the increased supply of domestic bonds while foreign reserves fall since the domestic residents diversify out of domestic asset into forelgn asset. In the case of this bond shock the trade-off faced by the central bank is clear: it can stabilize the interest rate through a domestic credit expansion at the cost of an even greater loss of reserves or it can stabilize the level of reserves by contracting domestic credit and pushing further up the level of the domestic interest rates. Again the choice of the central bank will depend on its relative preference for the interest rate and foreign reserve objectives. More formally the effect of the shock on domestic credit and reserves is:

$$
\begin{aligned}
& \frac{d D}{d B}-\frac{\left(1+\alpha^{2}\left(h_{0}+b_{0}\right) h_{0}\right)}{1+a^{2}\left(h_{0}+b_{0}\right)^{2}}<0 \\
& \frac{d R}{d B}-\frac{-1}{1+a^{2}\left(h_{0}+b_{0}\right)^{2}}<0
\end{aligned}
$$

Equation (27) implies that domestic credit will fall or rise depending on the following condition: 
$\frac{d D}{d B}<0$ for $\quad \alpha>\frac{1}{\left[\left(h_{0}+b_{0}\right) h_{0}\right]}(1 / 2)$

1.e. domestic credit will be expanded if the central bank cares more about interest rate smoothing while it will be contract if it prefers to preserve the level of reserves. Condition (28) shows, however, that independently of whether domestic credit is expanded or contracted, foreign reserves will fall: if domestic credit is expanded the impact loss of reserves is reinforced by the fall of reserves engineered by the domestic credit expansion; if domestic credit is contracted the impact loss of reserves dominates the secondary positive effect on reserves coming from the monetary contraction.

As in the case of a foreign interest rate and current account shocks, this result implies that a bond financed fiscal shock will lead to the observation of negatively correlated comovements of foreign reserves and domestic credit if the central bank is concerned about stabilizing interest rates and positive comovements if the central bank leans towards stabilizing foreign reserves. In the extreme case of perfect capital mobility, interest rates are pegged to the foreign ones and no change occurs in either foreign reserves or domestic credit, i.e. :

$\frac{d r}{d B}=\frac{d D}{d B}-\frac{d R}{d B}=0$


D. A domestic output shock

As a last case we will consider a domestic output shock (a change in $Y$ ). The impact effect of the shock is to increase domestic interest rates (through its positive effect on money demand) (see equation (8)) and increase foreign exchange reserves (equation (9)) as the increased money demand and interest rate lead to a capital inflow. In order to avoid the deviations of interest rates and foreign reserves from their targeted levels, the central bank will have to unambiguously increase domestic credit because such a monetary expansion will reduce both interest rates and foreign reserves. Formally the optimal response of domestic credit and reserves will be:

$$
\frac{d D}{d Y}-\frac{-b_{2}+\alpha^{2}\left(b_{0}+h_{0}\right)\left(h_{2} b_{0}-h_{0} b_{2}\right)}{1+a^{2}\left(h_{0}+b_{0}\right)^{2}}>0
$$

$$
\frac{d R}{d Y}\left(\frac{\left(h_{2}+b_{2}\right)}{1+\alpha^{2}\left(h_{0}+b_{0}\right)^{2}} !>0\right.
$$

Equations (30)-(31) show that the optimal reaction of domestic credit and foreign reserves is unambiguous: they both increase. Domestic credit must increase in order to reduce interest rate and reserves to their pre-shock levels while reserves increase on net because the primary positive effect of the shock on reserves dominates the 
secondary negative effect coming from the increase in domestic credit. It then follows that in the case of an output shock domestic credit and foreign reserves will comove in the same direction.

\section{Conclusions}

The objective of this paper was to explain the large negatively correlated comovements of domestic credit and foreign exchange reserves found in the analysis of sterilization policies under fixed exchange rates and in the EMS experience. It was shown that such correlations can be explained in a model where the central bank tries to smooth the short run fluctuations of domestic interest rates and foreign exchange reserves under fixed exchange rates. In particular, under a wide range of domestic and foreign disturbances the optimal response of the central bank will lead to negatively correlated comovements of domestic credit and foreign reserves if the central bank cares more about the interest rate smoothing objective relative to the foreign exchange reserve stabilization goal. These disturbances include foreign interest rate shocks, current account shocks and fiscally induced increase in domestic bonds. Conversely, positively correlated comovements of domestic credit and foreign reserves will be observed if the foreign exchange reserve objective is dominant. The results are obtained under the assumption the domestic and foreign assets are not perfectly substitutable. In this case the central bank is able to maintain some degree of control on its interest rates through the domestic credit instrument (the offset coefficient is smaller than minus one in 
absolute value). In the limiting case of perfect capital mobility, the domestic central bank has no control on its domestic interest rate and its domestic credit policy will be aimed at maintaining the targeted level of foreign reserves.

The implications of these results are that, as long as capital is not perfectly mobile and asset not perfectly substitutable, even a small "follower" country in a fixed exchange rate system like the EMS is going to be able and will optimally "sterilize" the effects on its money supply of changes in foreign reserves generated by a number of disturbances. This sterilizing response will occur if the objective of stabilizing domestic interest rate in the short run dominates the objective of maintaining a certain level of foreign reserves. The analysis also implies that the optimal degree of "sterilization" is not constant but rather depends on the type of shock that disturbs the economy. In this sense the sterilization and offset functions found in the literature do not fully consider the nature of the stabilization problem faced by a monetary authority in a fixed exchange regime. An empirical test of the model presented in this paper is certainly the next step to be considered. 


\section{References}

Aoki, M. "A Note on the Stability of the Interaction of Monetary Policy", Journal of International Economics, 7.

Argy, V. and P. Kouri (1974) "Sterilization Policies and the Volatility in International Reserves", in R.2. Aliber ed. National Monetary Policies and the International Financial System, University of Chicago Press, Chicago.

Barro, R. (1988) "Interest Rate Smoothing", mimeo, Harvard University, 1988. De Grauwe, P. (1975) "The interaction of Monetary Policy in a a Group of European Countries", Journal of International Economics, 5.

Giavazzi, F. (1987) "Exchange Controls and Sterilization: The German Experience and Lessons for Korea", mimeo.

Giavazzi, F. and A. Giovannini (1988 a) Models of the EMS: Is Europe a Greater Deutsche-Mark Area ?", in R. Bryant and R. Portes eds. Global Macroeconomics: Policy Conflict and Cooperation, McMillan Press, London.

Giavazzi, F. and A. Giovannini (1988 b) "Is Europe a Greater Deutsche-Mark Area ?". Chapter 4 in Limiting Exchange Rate Flextbility: The European Monetary System, forthcoming.

Hamada, K. (1985) The polit1cal Economy of International Monetary Interdependence, MIT Press.

Herring, R.J. and R.C. Marston (1977 a) "Sterilization Policy: The Trade-off 
between Monetary Autonomy and Control over Forelgn Exchange Reserves", European Economlc Review, 10.

Herring, R.J. and R.C. Marston (1977 b) National Monetary Polfcles and International Financial Markets, Amsterdam, 1977.

Kouri, P. (1975) "The Hypothesis of Offsetting Capital Flows - A Case Study of Germany", Journal of Monetary Economics, 1.

Kouri, P. and M. Porter (1974) "International Capital Flows and Portfolio Equilfbrium", Journal of Political Economy, May/June, 82.

Marston, R. (1980) "Cross Country Effects of Sterilization, Reserve Currencies and Foreign Exchange Intervention", Journal of International Economics, 10 .

Mastropasqua, C., S. Micossi and R. Rinaldi "Interventions, Sterilization and Monetary Policy in EMS Countries" paper presented at the Conference on the EMS organized by CEPR and the Banca d'Italia, Perugia, Italy, October $16-17,1987$.

Neumann, M. (1978) "Offsetting Capital Flows: A Reexamination of the German Case", Journal of Monetary Economics, 4.

Neumann, M. (1984) "Intervention in the Mark/Dollar Market: The Authorities' Reaction Function", Journal of International Money and Flnance, vol.3.

Obstfeld, M. (1978) "Sterilization and offsetting Capital Movements:

Evidence from West Germany, 1960-1971", unpublished manuscript, M.I.T.

Obstfeld, M. (1982 a) "Exchange Rates, Inflation, and the Sterilization Problem: Germany, 1975-1981", European Economic Review.

Obstfeld, M. (1982 b) "Can We Sterilize: Theory and Evidence", American Economic Review, May.

Padoan, P. (1984) "The European Monetary System: Pyramid or ECU ?", mimeo. 
RoubInI, N. (1986) "Strategic Pollcy Interactions In a Three Country Model", unpublished, Harvard UnIversity, October.

Roubini, N. (1987) "An Empirical Study of the EMS Realignments", unpublished, Harvard University, January.

Roubini, N. (1988 a) "Sterilization Policies, Offsetting Capital Movements and Exchange Rate Intervention Policles in the EMS". Chapter 4 of unpublished Ph.D. Dissertation, Harvard University, May.

Roubini, N. (1988 b) "Leadership and Cooperation under Alternative Exchange Rate Regimes: A Simulation Approach", Chapter 3 of unpublished Ph.D. Dissertation, Harvard University, May.

Roubini, N. (1988 c) "International Transmission of Macro Policles under Alternative Exchange Rate Regimes: A Four Country Model", unpublished, Harvard UnIversity.

Scholl, F. (1981) "Praktische Erfahrungen mlt dem Europalschen Wahrungssystem", In W. Ehrlicher and R. Richter (eds.) Probleme der Wahrungspolitik, Berlin, 1981, Pp.151-171.

Vaubel, R. (1980) "The Return to the New European Monetary System Objectives, Preferences, Perspectives", Carnegie-Rochester Conference Series on Public Polley, Autumn, 13. 